\title{
13. EFFECTS OF GAS AND CORE HANDLING ON MEASUREMENTS OF COMPRESSIONAL WAVE VELOCITY IN SITE 893 CORES ${ }^{1}$
}

\author{
Niall C. Slowey ${ }^{2}$ and William R. Bryant ${ }^{2}$
}

\section{INTRODUCTION}

The velocity of compressional waves in marine sediments depends upon the physical and geologic properties of the sediments. These properties and, in turn, velocity, depend upon the oceanographic and sedimentary processes existing at the time the sediments are deposited. Long, detailed proxy records of how these processes change through time can be quickly generated using routine measurements of velocity in whole sediment cores. However, once cores are split for description and discrete sampling, such measurements are no longer possible. Cores recovered by the Ocean Drilling Program (ODP) are usually split aboard the JOIDES Resolution, so the opportunity for extensive shore-based measurements of velocity seldom exists. Such an opportunity did exist in the case of cores from Site 893 in the Santa Barbara Basin because they were transported unopened from the ship to the ODP core repository in College Station, Texas (Shore-based Scientific Party, 1994a).

We undertook the shore-based measurement of the compressional wave velocity in cores from Site 893 for two reasons. First, we wanted to compare measurements made by the JOIDES Resolution corelogging system with those made by the GEOTEK core-logging instrument at Texas A\&M University. Second, we were interested in the rapidly accumulating, varved sediments in the Santa Barbara Basin because they contain a unique high-resolution record of environmental change during the late Quaternary (Shore-based Scientific Party, 1994b). Unfortunately, sediments from Site 893 contained dissolved methane which expanded into gas when cores were brought aboard the JOIDES Resolution (Shore-based Scientific Party, 1994b). This gas and, to a much lesser extent, the manner in which it was handled made it impossible for either the JOIDES Resolution or the Texas A\&M University core-logging instruments to measure the true compressional wave velocity of the sediments. Our purpose here is to examine how gas expansion and core handling affected velocity measurements and to consider possible ways of dealing with these effects at future ODP sites.

\section{METHODS AND RESULTS}

When cores from Site 893 were raised to the deck of the JOIDES Resolution, pressure due to expansion of biogenic methane gas forced sediment out of the core liners, so members of the shipboard party vented the gas by drilling holes in the liners at regular intervals (Shore-based Scientific Party, 1994b). The compressional wave velocity of several core sections was measured aboard the JOIDES Res-

'Kennett, J.P.. Baldauf, J.G., and Lyle, M. (Eds.), 1995. Proc. ODP, Sci. Results, 146 (Pt. 2): College Station, TX (Ocean Drilling Program).

'Department of Oceanography, Texas A\&M University, College Station. TX 77843, U.S.A. olution by members of the shipboard party following standard procedures (Shore-based Scientific Party, 1994a). These measurements were not available to us at the time we attempted shore-based measurements. A refrigerated, air-cushioned truck transported cores to the ODP repository in College Station, Texas, where they were placed in refrigerated storage until being moved to our laboratory at the nearby Oceanography Department at Texas A\&M University (Shore-based Scientific Party, 1994a). Due to time constraints related to the sampling schedule of other shore-based party members, our efforts were limited primarily to cores from Hole 893B.

Gas expansion created small voids as well as cracks oriented parallel to bedding (Shore-based Scientific Party, 1994b). The cracks typically extended up to several centimeters across the cores and from a few millimeters to over $10 \mathrm{~cm}$ along the axis of the cores. Gas expansion created air-filled gaps between portions of the sediment and the core liners. Figure 1 shows examples of voids, cracks and gaps. We noted that the vent holes in the liners had never been sealed aboard the JOIDES Resolution, so it is possible that some evaporation of sediment pore water occurred while the cores were being transported and stored.

The cores were allowed to warm to room temperature and compressional wave velocity measurements were made using a multisensor core-logging device manufactured by Peter Schultheiss of GEOTEK. The method is like that employed aboard the JOIDES Resolution (Schultheiss and McPhail, 1989): A core section is set on a track such that $\sim 500-\mathrm{kHz}$ acoustic traducers are flush against each side of the core. The core is moved along the track, stopping at preset intervals for measurements of the outer diameter of the core and the time it takes for a pulse to travel through the device, the core liner, and the sediments. Traveltime through the liner and electronics (found using a core liner filled with distilled water of known temperature) is subtracted from the total traveltime to find the apparent time taken by the pulse to travel through the sediments. Velocity is calculated assuming the pulse follows a straight path across the core. To correct velocity values from room temperature to $20^{\circ} \mathrm{C}$, the ratio of the change in velocity to the change in temperature was taken to be 3 $\mathrm{m} / \mathrm{s} /{ }^{\circ} \mathrm{C}$.

Velocity measurements were taken at 3-cm intervals. Figure 2 displays the compressional wave velocities calculated based upon pulse traveltimes measured at Texas A\&M together with the relative amplitude of the received pulse. Calculated velocities generally fall within a relatively consistent range of $\sim 880$ to $1000 \mathrm{~m} / \mathrm{s}$ and have very low pulse amplitudes (for completeness sake, the $\sim 500 \mathrm{~m} / \mathrm{s}$ values which occur at breaks between core sections due to the presence of core caps have not been edited out of the record). The amplitude of the received pulse was so low that in some instances the first peak of the pulse was below the threshold detection limit, resulting in spurious step changes in calculated velocity. Velocities calculated using measurements made aboard JOIDES Resolution (F. Rack, pers. comm., 1993) are similar to those made on shore. These calculated velocities are not representative of the true velocity of compressional waves in Site 893 sediments. 


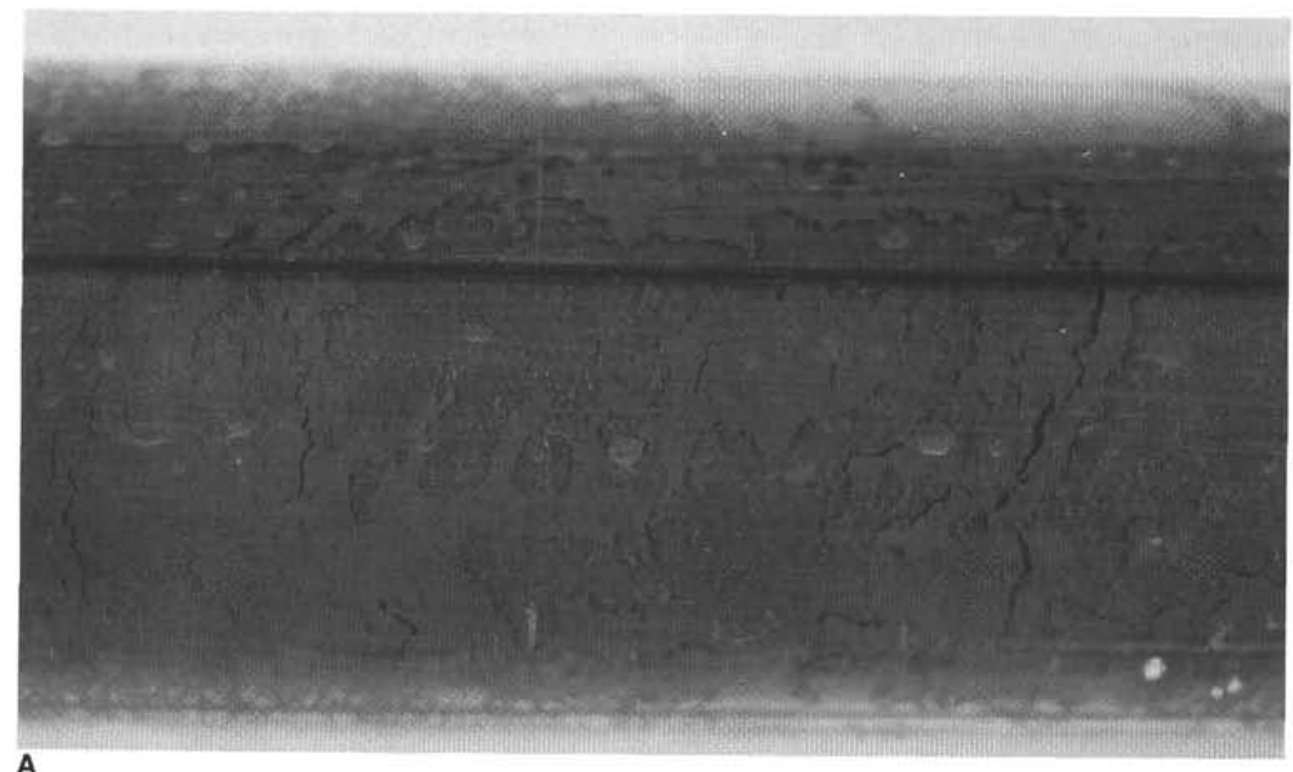

A

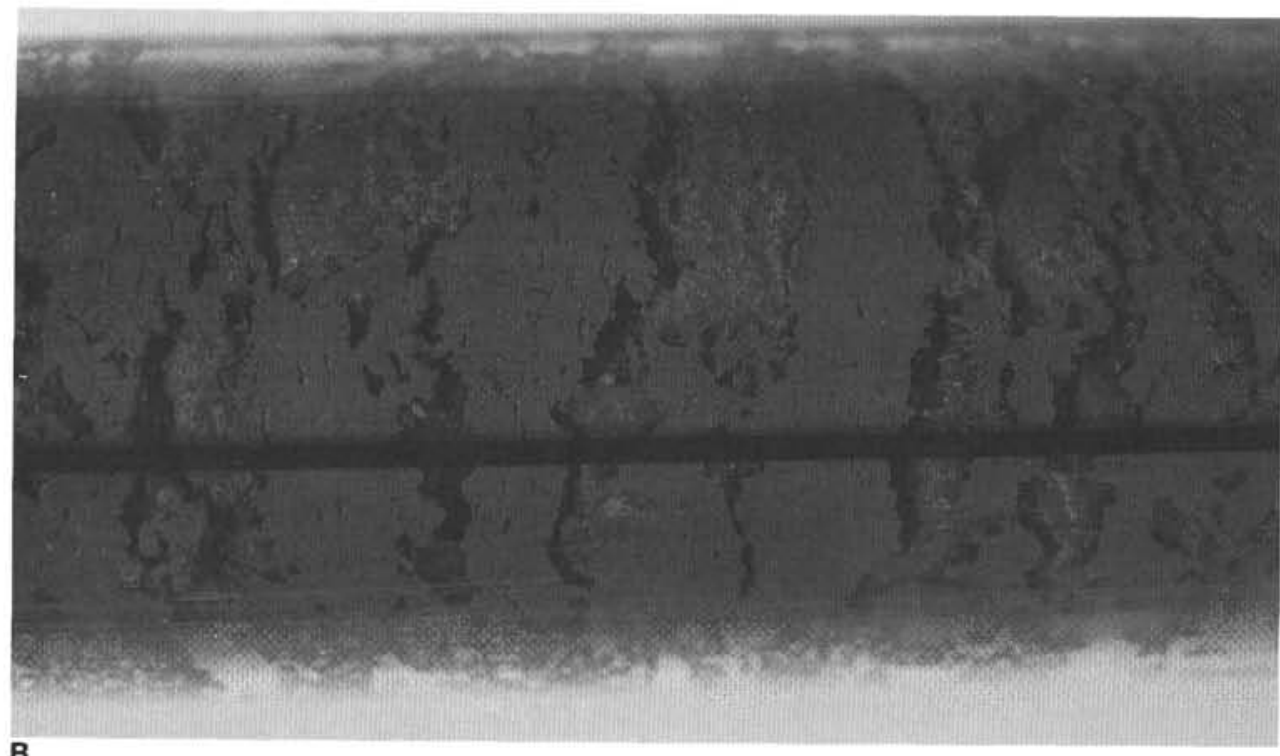

B

Figure 1. Photographs illustrating several effects of gas expansion on cores from Hole 893B. A. Air-filled gaps between the core liner and sediment. B. Voids and cracks oriented along bedding planes that extend partially across the core. $\mathrm{C}$. Cracks oriented along bedding planes that extend completely across the core. D. Large air-filled gaps separating sections of sediment.

\section{DISCUSSION}

Calculated compressional wave velocities in the gassy sediments of Site 893 are significantly less than the $\sim 1500 \mathrm{~m} / \mathrm{s}$ values generally observed in cohesive, fine-grained terrigenous sediments. Pulse amplitudes are also significantly lower than we have observed in nongassy sediments.

There are several mechanisms by which gas expansion and core handling might lead to the low values of velocity and wave amplitude in Site 893 cores:
1. Reduced compressibility and shear strength of sediment. Gasfilled voids and cracks increase the sediment's compressibility and decrease its shear strength, resulting in lower wave velocity and greater attenuation of the wave pulse. At least two processes could bring about gas-filled voids: gas expansion creating new voids, or evaporative loss of water from pores and concurrent filling of pores with air.

2. Longer travel path through sediments. Velocity is calculated under the assumption that the path the wave pulse takes through the sediments is straight across the core. However, if 


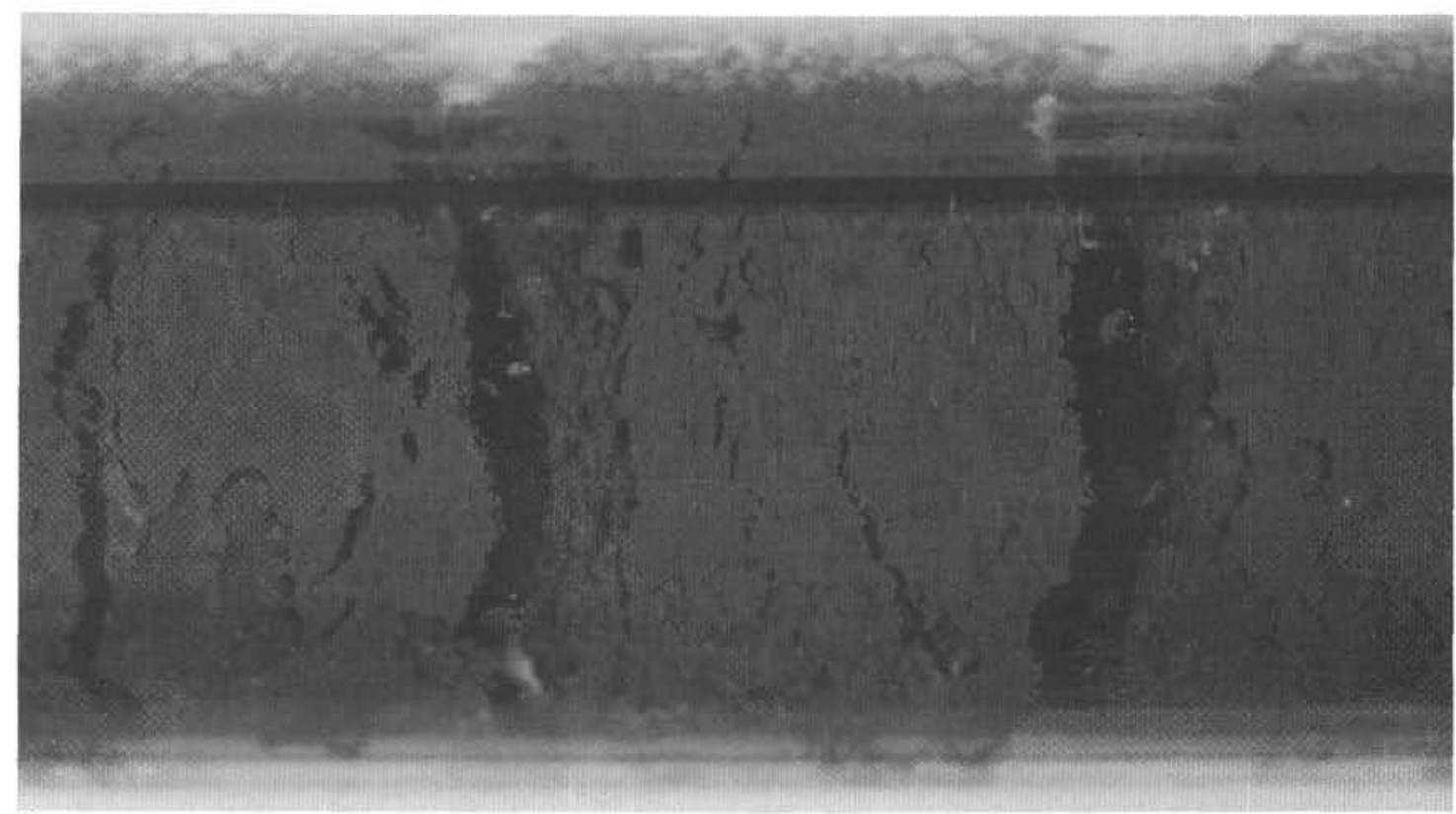

\section{C}

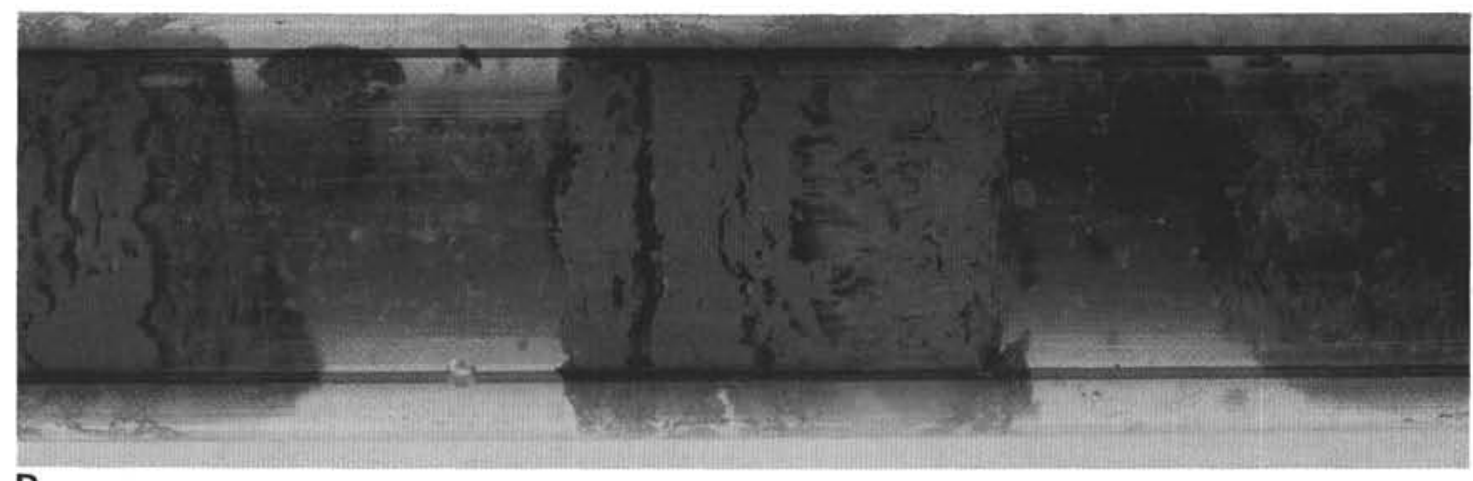

D

Figure 1 (continued).

the pulse actually takes a longer, indirect path around voids and expansion cracks, the calculated velocity is less than the true value. The voids and cracks can reduce pulse amplitude by absorbing and scattering wave energy as it travels through the sediments.

3. Propagation through air. Where gas expansion produced large air-filled gaps, the wave propagates through air in order to cross the core. Since there is a large difference between the acoustic impedances of core liner and air, little wave energy is transmitted straight across core.

4. Poor liner-sediment coupling. Along portions of the cores that contain sediment, the core liner and sediment may not be in direct contact due to the presence of small air gaps. Because the acoustic impedance of air is much less than either the core liner or sediment, wave energy is prevented from crossing the gaps and being transmitted straight across cores. Several processes may have contributed to gap formation: gas expansion forced water from the cores, gas expansion stretched the liner radially, evaporation of pore waters both into methane gas and into the atmosphere through unsealed venting holes, and shrinkage of sediments following loss of water.
We believe that mechanisms 1,2, and 3 above are not the primary cause of the low velocities and amplitudes in the Site 893 cores. If mechanism 3 were important, the calculated velocity should be the same as the velocity of sound in air $(\sim 345 \mathrm{~m} / \mathrm{s})$, but this is not the case. The amount that mechanisms 1 and 2 reduce the amplitude of transmitted waves and the magnitude of velocity should vary depending upon sediment characteristics like their fabric and composition, the geometry and extent of voids and cracks, and changes in water content, yet the values of velocity and pulse amplitude are very similar at all depths. This leaves mechanism 4 as the only remaining possibility. The primary effect of mechanism 4 on velocity is to prevent wave energy from being transmitted across cores.

What happens to this energy? A clue is provided by the fact that the primary frequency of the received pulse was several times lower than the signal generated by the source transducer. The decrease in frequency and amplitude suggests that the wave energy does not travel straight across the core, but instead, propagates around the core liner in the form of a surface wave. This longer path and mode of propagation would require more time than is taken by a compressional wave traveling straight across the core, so the calculated velocity would be less. The constancy with depth in the core of calculated ve- 


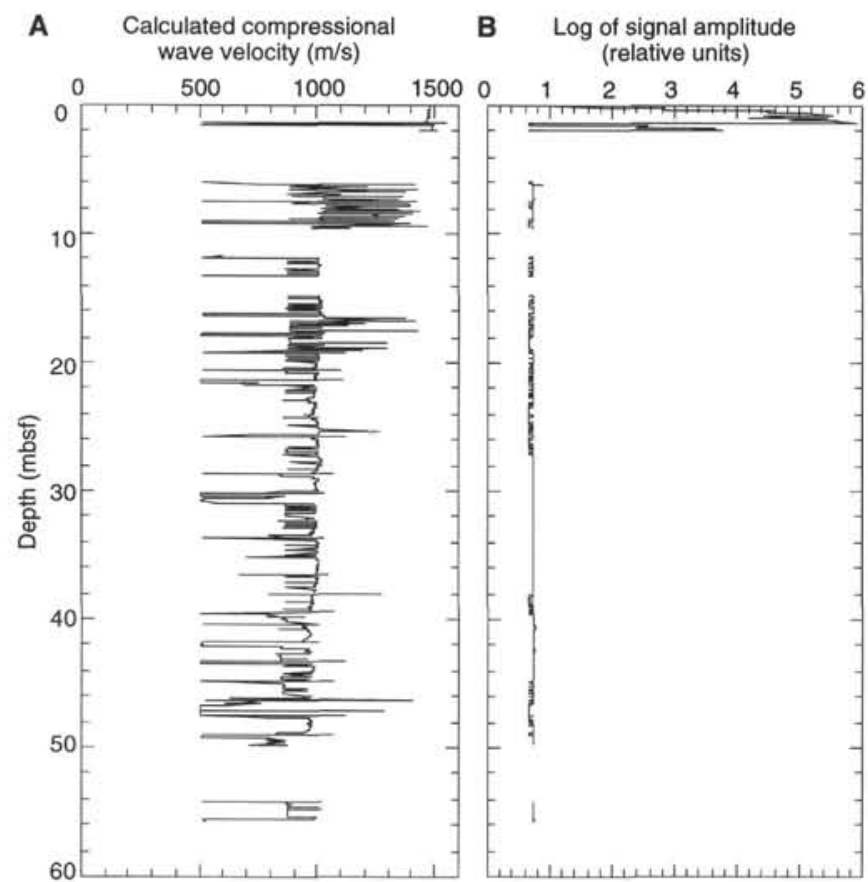

Figure 2. The calculated velocities (A) and measured pulse amplitudes (B) for the gassy sediments in Hole 893B. Velocity calculations assume compressional waves follow a straight path across the core. Since this was not actually the case, these values are not representative of the true compressional wave velocity of the sediments.

locity and pulse amplitude is consistent with the fact that liner composition and dimensions are essentially the same in all cores. Figure 3 shows the shapes of the received pulse in two cases: an ODP core liner filled with water and an ODP core liner filled with air. Notice that the frequency of the pulse received from the water-filled core is $\sim 465 \mathrm{kHz}$ while the dominant frequency of the pulse received from the air-filled core liner is more than four times lower $(\sim 100 \mathrm{kHz})$. The shapes and frequencies of the pulses received from the air-filled core liner and the Site 893 cores are similar and their amplitudes are several orders of magnitude less than those of pulses received from the water-filled core liner or from typical cores of nongassy marine sediments. The calculated velocity at $20^{\circ} \mathrm{C}$ that corresponds to the measured traveltime in the air-filled core is $\sim 1010 \mathrm{~m} / \mathrm{s}$, which is essentially the same as the typical values calculated for Site 893.

Thus, poor acoustic coupling due to the presence of air gaps between the sediments and liners appears to be the primary reason why it was not possible to determine the true velocity of compressional waves in sediments in the Site 893 cores. The fact that the shipboard measurements of velocity made shortly after core recovery were not successful indicates that the gaps formed directly as a result of gas expansion during core recovery or shortly thereafter, either while the cores were being vented or while the cores were awaiting shipboard measurement of traveltimes. Evaporation of water and loss of it via unsealed vent holes during the weeks the cores remained in storage prior to shore-based measurements and sampling may have aggravated shore-based difficulties at measuring velocity and might adversely affect the determination of other sediment physical properties such as water content and bulk density.

With the technology now available aboard the JOIDES Resolution, it seems that gas expansion during core recovery and the subsequent need for drilling vent holes cannot be avoided. This situation is not likely to change in the foreseeable future, so when gas is encoun-

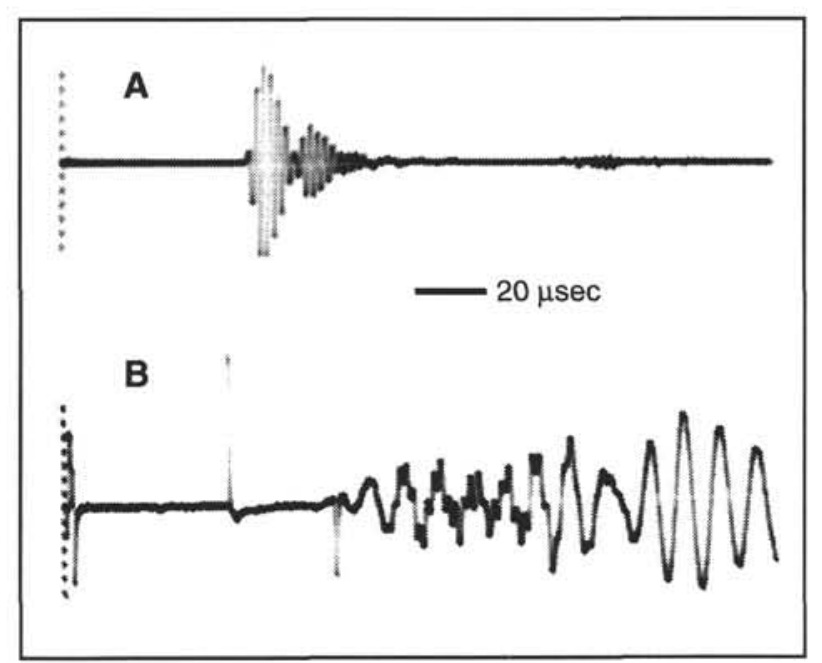

Figure 3. A comparison of the typical shapes of compressional wave pulses received from a water-filled ODP core liner (A) (pulse shape is similar in shape to that which normally propagates through sediments) and an air-filled ODP core liner (B) (pulse shape is similar to that observed during measurement of Site 893 core sections). These are line drawings taken from an oscilloscope for illustrating the shape of the pulses in a qualitative fashion. The relative horizontal scales (see figure) are consistent between (A) and (B), but the vertical scales are definitely not. The true amplitude of $(\mathrm{A})$ is about eight orders of magnitude greater than (B).

tered at future ODP sites it may again be difficult to effectively measure the compressional wave velocity in cored sediments. Under such circumstances, it would seem particularly desirable to deploy the downhole logging tools to attempt in situ measurements of velocity. It is also important to seal vent holes drilled in liners as soon as possible to prevent avoidable evaporative loss of water from the cores and minimize the effect of such loss on the determination of sediment physical properties. If measurements of the compressional wave velocity of gassy sediments in cores are required, problems associated with poor liner-sediment coupling could be reduced by carrying out measurements on split cores. For automated measurements, the latest core-logging instruments have transducers located above and below the core so the upper transducer would come into direct contact with the sediment (e.g., GEOTEK). For manual measurements, two transducers can be mounted on probes and inserted directly into the sediment (e.g., Baldwin et al., 1981).

\section{ACKNOWLEDGMENTS}

We thank J. Miller of the ODP repository in College Station, Texas, for his help transporting the cores between ODP and the Department of Oceanography; E. Polgreen for help with the core logger; $\mathrm{K}$. Davis and S. Drews for help graphing and formatting text; and A. Anderson and $\mathrm{A}$. Rutledge for stimulating discussions. The manuscript benefited from reviews by J. Baldauf, M. Lyle, and P. Schultheiss. This work was supported by NRL grants N00014-92-J2011 and N00014-93-1-6008 (Task 1).

\section{REFERENCES}

Baldwin, K.C., Celikkol, B., and Silva, A.J., 1981. Marine sediment acoustic measurement system. Ocean Eng., 8:481-488. 
Schultheiss, P.J., and McPhail, S.D., 1989. An automated $P$-wave logger for recording fine-scale compressional wave velocity structures in sediments. In Ruddiman, W., Sarnthein, M., et al., Proc. ODP. Sci. Results, 108: College Station, TX (Ocean Drilling Program), 407-413.

Shore-based Scientific Party, 1994a. Santa Barbara Basin explanatory notes. In Kennett, J.P., Baldauf, J.G., et al., Proc. ODP, Init. Repts., 146 (Pt. 2) College Station, TX (Ocean Drilling Program), 5-12. 1994b. Site 893. In Kennett, J.P., Baldauf, J.G., et al., Proc. ODP, Init. Repts., 146 (Pt. 2): College Station, TX (Ocean Drilling Program), $15-50$.

Date of initial receipt: 6 September 1994

Date of acceptance: 7 March 1995

Ms 146SR-306 